\title{
Calidad proteica en las fracciones de molienda de rodillos de trigo (T. aestivum) a nivel comercial
}

\author{
Protein quality in wheat (T. estivum) commercial roller milling streams
}

\begin{abstract}
Oscar Moreno-Araiza', Patricia Isabel Torres-Chávez ${ }^{1 *}$, Benjamín Ramírez-Wong ${ }^{1}$, Elisa Magaña-Barajas², Beatriz Montaño-Leyva ${ }^{1}$, Concepción Lorenia Medina-Rodriguez ${ }^{1}$, Javier Delgado-Rodriguez ${ }^{3}$

Departamento de Investigación y Posgrado en Alimentos, Universidad de Sonora, Rosales y Blvd. Luis Encinas, C.P. 83000, Hermosillo, Sonora, México.

2 Programa de Ingeniería en Tecnologías de Alimentos, Universidad Estatal de Sonora, Perimetral y Ley Federal del Trabajo s/n Colonia Apolo, C.P. 83100, Hermosillo, Sonora, México.

Gerente de Calidad, Grupo Munsa, S.A. de C.V., Hermosillo, Sonora, México.
\end{abstract}

\section{RESUMEN}

Las proteínas en la harina de trigo juegan un papel muy importante en la funcionalidad y calidad de sus productos, por lo que es importante conocer como se segregan en las diferentes corrientes de la molienda de rodillos. Se analizaron 23 corrientes de harinas de trigo (T. aestivum) de un sistema de molienda comercial. Se utilizó SDS-PAGE para estudiar a las subunidades de gluteninas y las subclases de gliadinas, encontrándose diferencias en la composición de las gliadinas omega. Se cuantificaron la proteína total (PT) y proteína polimérica insoluble (PPI), encontrándose variación de 11.56 a 18.41 \% (bs) y 5.32 a 10.54 \% (bs). Se usó (SE-HPLC) para estudiar las fracciones: proteína polimérica soluble (PPS), gliadinas, albuminas y globulinas, observándose diferencias en el patrón de separación y en la cantidad presente en las harinas. Además, se analizó la funcionalidad de las harinas con la prueba de sedimentación, obteniendo valores de 4.9 a $41 \mathrm{~mL}$. Las diferencias en cantidades encontradas son en parte información confirmatoria; sin embargo, diferencias en composición, especialmente la relacionada con Gliadinas omega gliadinas son contribución del presente trabajo.

Palabras clave: Fracciones de molienda, proteínas, molienda de rodillos, gliadinas omega.

\section{ABSTRACT}

The protein present in wheat flour plays a very important role in the functionality and quality of the baking products. It is important to know how this grain component segregates in the different streams of the wheat roller milling. We analyzed twenty-three wheat ( $T$. aestivum) flours from a commercial milling system by SDS-PAGE, to identify differences in protein components such as glutenin subunits and gliadin subclasses; finding differences in the composition of omega gliadins. Total protein (PT) and insoluble polymeric protein (PPI) were quantified by a nitrogen analyzer, with a variation of results of 11.56 to $18.41 \%(\mathrm{db})$ and 5.32 to 10.54 $\%(\mathrm{db})$. High performance molecular exclusion liquid chromatography (SE-HPLC) produced information of the soluble polymeric proteins (PPS), gliadins, albumins and globulins fractions, observing qualitative and quantitative differences. Flour functionality was analyzed with the rapid sedimentation test, obtaining values of 4.9 to $41 \mathrm{~mL}$. The difference in protein quality in the flours of the streams was demonstrated. Differences in quantity were in part confirmatory results. However, differences in quality, especially those related to omega gliadins is a contribution to the knowledge of this work.

Keywords: Milling streams, proteins, roller milling, omega gliadins.

\section{INTRODUCCIÓN}

En el devenir del tiempo, el trigo, desde su domesticación, ha jugado un papel muy importante en la cultura alimentaria, brindando diferentes opciones de alimentos, entre ellos el pan (Shewry, 2009; Campbell et. al., 2007). La harina de trigo que se utiliza para la elaboración de productos de panificación se produce a través de un proceso de molienda que consiste en la separación del endospermo del germen y el pericarpio, seguido por una reducción gradual del tamaño de partícula. Los componentes anatómicos del grano de trigo tienen diferente composición, así como también el endospermo muestra un gradiente en sus componentes, principalmente de la proteína. El contenido de proteína se incrementa del centro del grano hacia la capa aleurona (Tosi et. al., 2011; Tosi et. al., 2018). Se han encontrado gradientes del 8 al $43 \%$ en el contenido de proteínas (Kent, 1966). Con estudios especializados de inmunolocalización, también se han encontrado diferencias en la distribución del tipo de proteínas; las gliadinas gamma y las subunidades de masa molecular alta se encuentran en mayor proporción en el centro del grano (Tosi, et. al., 2011) y como consecuencia un mayor contenido de proteína polimérica insoluble (Tosi et. al., 2011). Así, el centro del grano de trigo tiene menor contenido de proteínas, pero mejor calidad panadera. Durante el proceso de molienda, el grano de trigo sufre el rompimiento y reducción y la harina se purifica, dando como resultado, harinas de calidad diferente, y esto se ve afectado por el flujo de los productos y subproductos de la molienda, también 
por la calidad del grano o su mezcla; a su vez, esto afecta el contenido y tipo de proteína que determina la funcionalidad final de cada harina (Pomeranz, 1988; Nelson y McDonald, 1977). La genética de los granos es un factor determinante en su calidad; hasta el momento, las subuniades de gluteninas de masa molecular alta Dx5+Dy10 han mostrado una calidad superior, correlacionando de forma positiva con los volúmenes de panificación (Payne, et. al., 1980; Wang et. al., 2007). Además, la cantidad y distribución de proteínas a favor de las proteínas del gluten (gluteninas y gliadinas), en contraposición a proteínas solubles, albúminas y globulinas, han mostrado tener un potencial reológico superior en productos de panificación (Okrajková et. al., 2007; Wang et. al. 2007; Sakhare et. al. 2015).

Actualmente, la industria comercializa harina, producto de la mezcla de diferentes variedades de grano de trigo, de calidades diferentes; mezclando además las corrientes del molino, con el fin de producir harina de calidad aceptable. La cantidad de harina producida es el parámetro más importante, pero existe en el mercado una necesidad de harinas de calidad superior para productos específicos (Campbell et. al., 2007; Brütsch et. al., 2017). Se puede emplear un método poco utilizado llamado "división de corrientes" (stream-splitting), que consiste en mezclar harinas con características similares, complementar la ausencia o cantidad de componentes de las que algunas harinas carecen para un uso específico (Dube et. al., 1987). Para poder emplear este método en la industria moderna, es necesario conocer la calidad proteica de cada una de las corrientes, el flujo de productos y subproductos en el proceso de molienda y el tipo de trigo a utilizar (Phrabhansankar et. al., 2000). La mayoría de los estudios de la distribución de las proteínas en las diferentes corrientes de molienda se ha hecho en molinos experimentales y se han encontrado concentraciones de proteína en las corrientes de molienda tan diferentes como 11 y $25 \%$ (Nelson y McDonald, 1977). Además, se ha relacionado el contenido de proteínas con calidad de panificación recientemente, usando métodos multivariados (Pojic et. al., 2014; Suresh y Neethirajan, 2015; Brütsch et. al., 2017), mostrando las diferencias de calidad que existen en las harinas de las diferentes corrientes de molienda.

El objetivo de esta investigación es identificar los componentes proteicos en las harinas de las corrientes de molienda en un molino comercial, usando técnicas de cromatografía y electroforesis, relacionándolo además con indicadores de calidad panadera.

\section{MATERIALES Y MÉTODOS Muestreo}

El estudio se llevó a cabo en un molino comercial del grupo MUNSA, S.A de C.V. Se muestrearon por triplicado cada una de las 23 corrientes productoras de harina y la mezcla como producto final. Las muestras se llevaron al laboratorio de Química de Cereales de la Universidad de Sonora, para ser analizadas.

\section{Proceso de molienda}

Al recibir el grano de trigo, se limpia en cribas industriales y se almacena en silos. Se hacen mezclas de las variedades para la obtención de una harina en particular. En este caso, se mezclaron tres variedades de trigo panadero que contienen las subunidades de gluteninas de masa molecular alta Dx5+Dy10 (resultado del análisis de subunidades de gluteninas, usando SDS-PAGE), relacionadas con una buena calidad panadera (Payne 1980).

Se hace un primer acondicionamiento a 14.0 - $14.5 \%$ de humedad, posteriormente se termina el proceso de limpieza del grano, removiendo piedras e impurezas pequeñas. Se continúa con el proceso de acondicionamiento hasta llegar a un $16-16.5 \%$ de humedad. Después del acondicionamiento, se pasa al primer sistema de rompimiento y se continua con el proceso de molienda. Este proceso de molienda seca se compone de tres sistemas básicos: rompimiento a través del uso de rodillos corrugados; reducción, con el uso de rodillos lisos; y purificación, usando purificadores y centrífugas. A través de un proceso complejo, se busca obtener la mayor cantidad de harina, separando el endospermo del pericarpio y germen y reduciendo el tamaño de partícula. Se obtiene harina de los diferentes pasajes, con características fisicoquímicas y nutricionales diferentes; además, se obtienen productos intermedios que son sometidos a otro pasaje de molienda. El salvado y germen se remueven. Al final, la harina blanca se mezcla, se fortifica con vitaminas y opcionalmente se agregan aditivos.

\section{Análisis de componentes químicos}

El contenido de cenizas en cada una de las muestras de harina de trigo proveniente de las corrientes y producto final se determinó con el método de AACC 08-01.01; la temperatura y tiempo del procedimiento fueron $550^{\circ} \mathrm{C}$ por $24 \mathrm{~h}$. El contenido de humedad se determinó por diferencia de pesos, después del calentamiento a $100^{\circ} \mathrm{C}$ por 12 horas, usando el método AACC 44 - 40. El contenido de proteína de las harinas fue determinado con un analizador de nitrógeno (LECO FP - 528, St. Joseph, MI). Para la conversión de los valores de nitrógeno se uso un factor de conversión de 5.7.

\section{Contenido de proteína polimérica insoluble (PPI)}

Se determinó el contenido de PPI en las harinas, cuantificando el contenido de proteínas en el pellet resultante de la extracción exhaustiva de las proteínas solubles en propanol al 50 \% (Bean et. al., 1998). El procedimiento para la determinación de proteínas en el pellet fue el mismo que el usado para la determinación de proteínas en las harinas.

\section{Índice de sedimentación}

Se determinó el índice de sedimentación, que representa la capacidad de hidratación y de expansión de las proteínas del gluten en un medio ligeramente ácido (AACCI 56-60.01). 


\section{Cromatografía liquida de exclusión molecular de alta resolución (SE-HPLC)}

Se realizó el análisis cromatográfico de acuerdo con el método de Bean et. al. (1998), con algunas modificaciones. Se tomaron $250 \mathrm{mg}$ de harina, que fueron mezcladas con un 1 $\mathrm{mL}$ de propanol al $50 \%$, en un agitador (Vortex Genie2, Scientific Industries, Bohemia, NY) durante 15 min, de manera continua. Después, las muestras se centrifugaron (Eppendorf AG, 5415 Hamburg) a $8000 \times$ g durante 5 min, y el sobrenadante fue recuperado. El sobrenadante fue centrifugado a 14,000 $x \mathrm{~g}$ durante 15 min y fue analizado por la cromatografía liquida de exclusión molecular de alta resolución. El sistema consiste en una bomba cuaternaria y un detector de arreglo de diodos (Agilent Technologies, Model 1260, Pittsburgh PA, USA), con una columna Biosep-SEC-S 4000 column (Phenomex, Torrence, $C A)$. La fase móvil fue de agua-acetonitrilo $(50: 50 \mathrm{v} / \mathrm{v})$ con $0.1 \%$ de ácido trifluoracético a un flujo de $0.8 \mathrm{~mL} \mathrm{~min}{ }^{-1}$. Las proteínas se detectaron a $280 \mathrm{~nm}$. El perfil cromatográfico fue analizado usando el software Open Lab Software (Agilent Technologies, Palo Alto, CA). Se realizó el análisis por triplicado, determinando el área bajo la curva de diferentes picos, se comparó con datos publicados (Bean et. al., 1998) para obtener la información de proteína polimérica soluble (PPS), gliadinas, albúminas y globulinas.

\section{SDS-PAGE}

Se realizó la electroforesis desnaturalizante y reductora en extractos de las harinas para estudiar todas las proteínas presentes, también se realizó la electroforesis en las proteínas remanentes en los pellets después de la extracción de las proteínas solubles en propanol al $50 \%$ con el fin de estudiar a las subunidades de las gluteninas. La extracción se realizó en $300 \mathrm{mg}$ de muestra con $1 \mathrm{~mL}$ de buffer (SDS $10 \%$, 2 mercaptoetanol $0.05 \%, 0.1$ azul de bromofenol $0.1 \%$, agua deionizada y $0.05 \mathrm{Tris}-\mathrm{HCl}$ con un $\mathrm{pH}$ de 6.8). La electroforesis, SDS-PAGE, se realizó de acuerdo con el método de Laemmli (1970), con algunas modificaciones. La corrida se realizó en un sistema de gel vertical, mini-protean 3 (Bio-Rad Corporation, Hercules, CA), usando geles de acrilamida al 10\%, a 100 $\mathrm{V}$ por aproximadamente $3 \mathrm{~h}$. Después el gel fue teñido con azul brillante de coomassie G-250 a temperatura ambiente $\left(25^{\circ} \mathrm{C}\right)$ con agitación y desteñido con metanol, $10 \%$ y de ácido acético glacial, $7 \%$.

\section{Diseño experimental y análisis estadístico}

El diseño experimental fue completamente aleatorio de un solo factor (corriente de molienda) con las variables respuesta: contenido de humedad, contenido de proteína, contenido de cenizas, contenido de PPI, índice de sedimentación, área bajo la curva cromatográfica en cada uno de los picos de las proteínas correspondientes a proteína polimérica soluble (PPS), gliadinas, albuminas, y globulinas.

Se llevaron a cabo análisis de varianza (ANOVA) y la diferencia entre medias se analizó con la prueba de Tukey, ambos procedimientos con un nivel de significancia del $95 \%$. Para reducir la dimensionalidad y poder observar gráficamen- te la relación de las variables y las corrientes de molienda, se hizo un análisis multivariado de componentes principales. Se usó XLstat 2019 para hacer los análisis estadísticos.

\section{RESULTADOS Y DISCUSIÓN \\ Distribución de cenizas y proteínas}

Como se muestra en la tabla 1, existen diferencias significativas $(p<0.05)$ en cada uno de los componentes químicos de las harinas de las corrientes o fracciones de molienda. El contenido de ceniza se encuentra entre 0.46-

Tabla 1. Principales componentes fisicoquímicos de las harinas de trigo. Table 1. Main physicochemical components of wheat flour.

\begin{tabular}{lccccc}
\hline Corrientes & HUM (\%) & $\begin{array}{c}\text { PPI (\%) } \\
\text { b.s. }\end{array}$ & $\begin{array}{c}\text { PT (\%) } \\
\text { b.s. }\end{array}$ & $\begin{array}{c}\text { CEN (\%) } \\
\text { b.s. }\end{array}$ & $\begin{array}{c}\text { SED } \\
\text { (ml) }\end{array}$ \\
\hline T1 & $14.01 \mathrm{a}$ & $5.77 \mathrm{i}$ & $13.20 \mathrm{k}$ & $0.64 \mathrm{ij}$ & $14.0 \mathrm{k}$ \\
\hline T2 & $14.0 \mathrm{a}$ & $6.59 \mathrm{~h}$ & $14.44 \mathrm{i}$ & $0.55 \mathrm{~lm}$ & $18.0 \mathrm{i}$ \\
\hline T3 & $13.91 \mathrm{a}$ & $7.87 \mathrm{ef}$ & $16.21 \mathrm{e}$ & $0.81 \mathrm{~h}$ & $18.8 \mathrm{~h}$ \\
\hline C1 H1 & $13.47 \mathrm{~b}$ & $5.32 \mathrm{i}$ & $12.66 \mathrm{~m}$ & $0.56 \mathrm{klm}$ & $19.9 \mathrm{~g}$ \\
\hline C2 H1 & $12.85 \mathrm{c}$ & $6.72 \mathrm{~h}$ & $12.31 \mathrm{no}$ & $0.56 \mathrm{klm}$ & $12.7 \mathrm{~m}$ \\
\hline C2 H3 & $12.7 \mathrm{~cd}$ & $6.76 \mathrm{gh}$ & $12.12 \mathrm{p}$ & $0.62 \mathrm{ijkl}$ & $12.7 \mathrm{~m}$ \\
\hline C3 H1 & $12.37 \mathrm{ef}$ & $8.13 \mathrm{de}$ & $11.87 \mathrm{q}$ & $0.54 \mathrm{klm}$ & $13.9 \mathrm{I}$ \\
\hline C3 H2 & $13.53 \mathrm{~b}$ & $10.08 \mathrm{ab}$ & $12.24 \mathrm{op}$ & $0.53 \mathrm{mn}$ & $13.9 \mathrm{I}$ \\
\hline C3 H3 & $10.78 \mathrm{k}$ & $9.72 \mathrm{bc}$ & $12.42 \mathrm{n}$ & $0.56 \mathrm{jklm}$ & $14.0 \mathrm{k}$ \\
\hline C4 & $11.10 \mathrm{j}$ & $9.81 \mathrm{bc}$ & $15.38 \mathrm{f}$ & $1.51 \mathrm{~d}$ & $30.0 \mathrm{~d}$ \\
\hline C5 H1 & $12.42 \mathrm{def}$ & $5.88 \mathrm{i}$ & $11.68 \mathrm{r}$ & $0.54 \mathrm{lmn}$ & $11.8 \mathrm{p}$ \\
\hline C5 H2 & $11.75 \mathrm{gh}$ & $6.85 \mathrm{gh}$ & $11.56 \mathrm{r}$ & $0.52 \mathrm{mn}$ & $11.8 \mathrm{p}$ \\
\hline C6 H1 & $11.47 \mathrm{hi}$ & $7.07 \mathrm{gh}$ & $18.84 \mathrm{a}$ & $2.04 \mathrm{~b}$ & $26.7 \mathrm{e}$ \\
\hline C6 H2 & $12.12 \mathrm{f}$ & $8.51 \mathrm{~d}$ & $12.32 \mathrm{no}$ & $0.62 \mathrm{ijkl}$ & $26.5 \mathrm{f}$ \\
\hline C7 U.C. & $12.86 \mathrm{c}$ & $7.38 \mathrm{fg}$ & $14.44 \mathrm{i}$ & $0.98 \mathrm{~g}$ & $10.8 \mathrm{r}$ \\
\hline C8 U.C. & $11.25 \mathrm{ij}$ & $8.33 \mathrm{de}$ & $13.79 \mathrm{j}$ & $1.04 \mathrm{fg}$ & $11.0 \mathrm{q}$ \\
\hline C9 U.C. & $10.99 \mathrm{jk}$ & $8.33 \mathrm{de}$ & $14.64 \mathrm{~h}$ & $1.52 \mathrm{~d}$ & $30.3 \mathrm{c}$ \\
\hline CDF & $11.22 \mathrm{ij}$ & $6.59 \mathrm{~h}$ & $15.15 \mathrm{~g}$ & $1.90 \mathrm{c}$ & $41.0 \mathrm{a}$ \\
\hline Centrifugo 2 & $10.23 \mathrm{I}$ & $10.54 \mathrm{a}$ & $16.55 \mathrm{~d}$ & $1.08 \mathrm{f}$ & $30.9 \mathrm{~b}$ \\
\hline Div 1 & $13.87 \mathrm{a}$ & $8.17 \mathrm{de}$ & $12.94 \mathrm{I}$ & $0.63 \mathrm{ijk}$ & $11.9 \mathrm{o}$ \\
\hline Div 2 & $11.81 \mathrm{a}$ & $7.00 \mathrm{gh}$ & $17.62 \mathrm{~b}$ & $1.33 \mathrm{e}$ & $8.9 \mathrm{~s}$ \\
\hline Div C. & $12.64 \mathrm{cde}$ & $6.68 \mathrm{~h}$ & $16.89 \mathrm{c}$ & $2.65 \mathrm{a}$ & $4.9 \mathrm{t}$ \\
\hline D1 & $14.13 \mathrm{a}$ & $9.35 \mathrm{c}$ & $12.13 \mathrm{p}$ & $0.46 \mathrm{n}$ & $17.0 \mathrm{j}$ \\
\hline Producto & $11.7 \mathrm{gh}$ & $10.03 \mathrm{ab}$ & $12.65 \mathrm{~m}$ & $0.67 \mathrm{i}$ & $12.0 \mathrm{n}$ \\
\hline & & & & & \\
\hline
\end{tabular}

*Nota: b.s., base seca; PPI: proteína polimérica insoluble; PT: proteína total; CEN: ceniza; SED: índice de sedimentación; T1: triturador 1; T2: triturador 2; T3: triturador 3; $\mathrm{C} 1 \mathrm{H} 1$ : corriente1, harina $1 ; \mathrm{C} 2 \mathrm{H} 1$ : corriente 2, harina 1; $\mathrm{C} 2 \mathrm{H} 3$ : corriente 3 , harina 3 ; $\mathrm{C} 3 \mathrm{H} 1$ : corriente 3 , harina 1; $\mathrm{C} 3 \mathrm{H} 2$ : corriente 3 , harina 2; $\mathrm{C} 3 \mathrm{H} 3$ : corriente 3, harina 3; $\mathrm{C} 4 \mathrm{U} . \mathrm{C}$ : corriente 4 ; $\mathrm{C} 5 \mathrm{H} 1$ : corriente 5 , harina 1; $\mathrm{C} 5 \mathrm{H} 2$ : corriente 5 , harina 2; $\mathrm{C} 6 \mathrm{H} 1$ : corriente 6 , harina 1 ; $\mathrm{C6} \mathrm{H2}$ : $\mathrm{CO}-$ rriente 6, harina 2; C7 U.C: corriente 7; C8 U.C: corriente 8; C9 U.C: Corriente 9; CDF: Centrífugo de fuerza; Div 1: divisor 1; Div 2: divisor 2; Div C: divisor cepillador; D1: reductor 1; Producto final, harina comercial. Dentro de una columna, promedios con la misma letra no muestran diferencias significativas $(p>0.05)$. 
$2.65 \%$, su variación dependió del sistema al que pertenece la harina, y el mayor contenido se encuentra en el sistema de purificación (Div 1, Div 2, Div C, CDF, Centrifugo 2) y la harina de las últimas corrientes de reducción ( $\mathrm{C} 6 \mathrm{H1}, \mathrm{C} 7, \mathrm{C} 8$, C9). Este componente presentó una tendencia de aumento desde el inicio hasta el final en cada uno de los pasajes de cada sistema; este último resultado coincide con lo reportado hasta el momento (Every et. al., 2002; Liu et. al., 2011). El incremento de ceniza indica contaminación con tejido no endospérmico y presencia de parte de la capa aleurona en la harina, lo que reduce su calidad panadera. El mayor contenido de proteínas de la harina se encontró en el sistema de purificación (Div C., Div 1, Div 2, CDF, Centrifugo 2), en el T3 y en los últimos rodillos de purificación ( $\mathrm{C} 6 \mathrm{H1}, \mathrm{C} 7, \mathrm{C} 8, \mathrm{C} 9)$, esta proteína proviene de la parte externa del endospermo cercana al pericarpio donde predominan las fracciones proteicas de albuminas y globulinas (Tosi et. al. 2011). El proceso progresivo de la molienda tiene un efecto de aumento en el nivel de extracción de harina y con ello aumento en las proteínas más cercanas al pericarpio, siendo esta harina de una calidad panadera menor, mientras que en los primeros rodillos del sistema de reducción (D1, C1 H1, C2 H1, C2 H3, C3 $\mathrm{H} 1, \mathrm{C} 3 \mathrm{H} 2, \mathrm{C} 3 \mathrm{H} 3, \mathrm{C} 4, \mathrm{C} 5 \mathrm{H} 1, \mathrm{C} 5 \mathrm{H} 2$ ) con un menor porcentaje de extracción de harina y un contenido menor de proteínas, se logran extraer los componentes provenientes de la parte interna del endospermo con una calidad panadera superior, y menor contaminación de ceniza (Brütsch et. al., 2017).

\section{Variación de los indicadores de calidad de panificación}

El contenido de PPI en las harinas de trigo se muestra en la tabla 1, los resultados presentan diferencias significativas $(p<0.05)$. La harina con un contenido de PPI mayor, es la del centrífugo 2 (10.54\%); probablemente en este pasaje se llega a la parte interna del grano, al centro del endospermo, con un contenido de PPI mayor. Este contenido es similar al del producto final $(10.03 \%)$, seguido de las corrientes del sistema de reducción C3 H1, C3 H2, C3 H3, C4 (8.13-10.08 \%). En los rodillos de trituración T1 (5.77 \%), T2 (6.59\%), T3 (7.87 \%) se observa una tendencia al aumento del contenido de PPI; resultados similares obtuvieron Prabhansankar et. al. (2000), debido al rompimiento gradual del grano de trigo acercándose más a la parte central del endospermo, hasta llegar a los rodillos de reducción, donde la extracción de PPI es superior (Tosi et. al., 2011). Wang et. al. (2007) reportaron que la relación de PPI a monomérica es mayor en los rodillos de rompimiento, teniendo una harina con mejor calidad de panificación, con un contenido mayor de gluteninas.

Los resultados del volumen o índice de sedimentación se encuentran en la tabla 1, mostrando diferencias significativas y valores que van de 4.9 a $41 \mathrm{~mL}$. Se hace evidente al observar los valores, la gran variación en calidad de las harinas de las diferentes corrientes. En general, esta evaluación fisicoquímica se utiliza para evaluar la calidad proteica (Pomeranz, 1988). Se observa que la cantidad y calidad de proteínas tienen una influencia importante, tal es el caso de las harinas CDF $(41 \mathrm{~mL})$, Centrifugo $2(30.9 \mathrm{~mL}), \mathrm{C} 4(30 \mathrm{~mL})$ y $\mathrm{C} 6 \mathrm{H} 1$ (26.73 mL) que muestran cantidad de PT de 15.14 - $18.84 \%$; además, son harinas con un contenido de PPI de $7.07-10.54 \%$ (tabla 1). Estos resultados sugieren que el tipo y la cantidad de proteína son importantes para la calidad de panificación. Resultados similares mostró Sakhare y col. (2015), donde se obtuvieron índices de sedimentación de 41 - $61 \mathrm{~mL}$ en 12 corrientes de trigo provenientes del sistema de rompimiento, purificación y reducción; el valor más alto fue el del triturador 4 y este resultado se relacionó directamente con el gluten seco encontrado en esa harina.

\section{Distribución de los componentes proteicos}

En la tabla 2 se presentan los resultados de SE-HPLC, se muestra el área bajo la curva en cada fracción proteica. Se observan diferencias significativas $(p<0.05)$ para cada una de las fracciones. También, claramente se puede ver en la figura 1, la diferencias en la distribución proteica en cada sistema de molienda; se identificaron 4 fracciones diferentes: proteína polimérica soluble (PPS), gliadinas, albuminas y globulinas (Bean et. al., 1998). Sutton y Simmons (2006) reportaron un análisis de proteínas de trigo suave por cromatografía liquida de exclusión molecular a corrientes de un molino harinero, planta piloto, donde se tomaron muestras de 14 corrientes, 4 de ellos de rodillos de trituración. En ese estudio (Sutton y Simmons, 2006), se demostró que la distribución proteica es diferente y que la fracción soluble de la glutenina y gliadinas es mayor en los rodillos de trituración, específicamente en el T1 y T2, y entre el T3 y T4 se reporto un descenso, en cambio en nuestro estudio la corriente con la fracción soluble de glutenina mayor fue la T3, mientras que en T1 y T2 fueron resultados similares, como se observa en la tabla 2. Esto debido al tipo de molino empleado, además de la variedad de los granos de características proteicas diferentes (Shewry, 2009).

La corriente $\mathrm{C} 6 \mathrm{H} 2$ presentó un valor muy bajo de PPS (tabla 2), acompañado de un valor relativamente alto de PPI (tabla 1) y un valor intermedio en el contenido de proteínas (tabla 1). Se observan además valores muy bajos de las otras proteínas solubles en esta muestra. El centrífugo 2 presentó un valor alto de PPS, un valor alto de PPI (10.54 \%) y un valor alto en el contenido de proteínas (16.55\%). Los valores de PPS dependen del contenido de proteínas de la harina y del contenido de PPI. En harinas con contenidos equivalentes de proteínas, valores bajos de PPS, pueden in dicar un mayor contenido de PPI y una buena calidad panadera. Aunque la homogeneidad en el contenido de proteínas no es el caso del presente estudio y no se pueden ver claramente estas relaciones al observar únicamente los valores de las tablas, si se puede observar al analizar los datos con estadística multivariada. Los valores de gliadinas siguieron un patrón muy parecido a la PPS; de hecho, mostraron un a correlación $\left(\mathrm{r}^{2}=\right.$ $0.72)$ muy significativa $(p<0.001)$. El contenido de albúminas mostró una correlación positiva $\left(r^{2}=0.69\right)$ muy significativa $(p<0.001)$ con el contenido de proteínas. Las harinas de las corrientes o fracciones de molienda con mayor contenido de proteínas tuvieron un mayor contenido de albúminas. 
Tabla 2. Área bajo la curva de las fracciones identificadas a través de la cromatografía liquida de exclusión molecular de alto rendimiento. Table 2. Area under the curve of the fractions identified through high performance molecular exclusion liquid chromatography.

\begin{tabular}{|c|c|c|c|c|}
\hline Corrientes & $\begin{array}{l}\text { PPS }\left(10^{-7}\right. \\
\text { UA) }\end{array}$ & $\begin{array}{l}\text { Gliadinas } \\
\text { (10-7 UA) }\end{array}$ & $\begin{array}{l}\text { Albuminas } \\
\left(10^{-6} \mathrm{UA}\right)\end{array}$ & $\begin{array}{c}\text { Globulinas } \\
\left(10^{-6} \text { UA }\right)\end{array}$ \\
\hline T1 U.C. & $15.6 \mathrm{efg}$ & $35.86 \mathrm{abcd}$ & $23.47 \mathrm{~g}$ & 16.59 def \\
\hline T2 U.C. & $15.81 \mathrm{cde}$ & 35.17 bcdef & $21.49 \mathrm{gh}$ & 18.34 cdef \\
\hline T3 U.C & $18.03 \mathrm{a}$ & $36.73 a b c$ & $22.66 \mathrm{~g}$ & 13.55 def \\
\hline $\mathrm{C} 1 \mathrm{H} 1$ & 13.28 hij & 34.88 cdefg & $19.46 \mathrm{hi}$ & 13.14 def \\
\hline $\mathrm{C} 2 \mathrm{H} 1$ & 13.83 fghij & $32.66 \mathrm{fgh}$ & $20.03 \mathrm{hi}$ & $18.78 \mathrm{cdef}$ \\
\hline $\mathrm{C} 2 \mathrm{H} 3$ & 13.67 ghij & 33.81 defg & $20.23 \mathrm{~h}$ & 13.97 def \\
\hline $\mathrm{C} 3 \mathrm{H} 1$ & 13.22 hijk & $35.68 \mathrm{abcd}$ & $21.36 \mathrm{gh}$ & $19.05 \mathrm{cdef}$ \\
\hline $\mathrm{C} 3 \mathrm{H} 2$ & 13.46 ghij & 35.35 abcde & $19.66 \mathrm{hi}$ & 13.49 def \\
\hline $\mathrm{C} 3 \mathrm{H} 3$ & 13.90 fghij & $35.72 \mathrm{abcd}$ & $20.36 \mathrm{~h}$ & 14.44 def \\
\hline C4 U.C. & $11.92 \mathrm{kl}$ & $29.61 \mathrm{i}$ & $32.15 \mathrm{~d}$ & $38.08 \mathrm{cde}$ \\
\hline $\mathrm{C} 5 \mathrm{H} 1$ & 13.93 fghij & $35.99 \mathrm{abcd}$ & $18.00 \mathrm{i}$ & 11.80 def \\
\hline $\mathrm{C} 5 \mathrm{H} 2$ & $13.19 \mathrm{ijk}$ & $32.46 \mathrm{gh}$ & $20.33 \mathrm{~h}$ & $75.95 \mathrm{ab}$ \\
\hline $\mathrm{C} 6 \mathrm{H} 1$ & 14.50 efgh & $35.52 \mathrm{abcd}$ & $41.08 \mathrm{~b}$ & $51.01 \mathrm{abc}$ \\
\hline $\mathrm{C} 6 \mathrm{H} 2$ & $5.67 \mathrm{~m}$ & $12.99 \mathrm{k}$ & $9.93 \mathrm{k}$ & $4.53 \mathrm{f}$ \\
\hline C7 & 15.05 def & $37.64 a b$ & $29.34 \mathrm{e}$ & 34.59 cdef \\
\hline C8 U.C. & $12.85 \mathrm{jk}$ & 32.86 efgh & 28.39 ef & $43.42 \mathrm{bcd}$ \\
\hline C9 U.C. & $11.45 I$ & $32.68 \mathrm{fgh}$ & $33.59 \mathrm{~cd}$ & $50.89 \mathrm{abc}$ \\
\hline Div 1 & 14.17 fghi & $36.17 \mathrm{abcd}$ & $22.94 \mathrm{~g}$ & 15.62 def \\
\hline Div 2 & $17.1 \mathrm{abc}$ & $37.94 a$ & $32.74 \mathrm{~cd}$ & 29.46 cdef \\
\hline Div C & $16.1 \mathrm{bcd}$ & $36.20 \mathrm{abcd}$ & $34.87 c$ & 27.36 cdef \\
\hline Centrifugo 2 & $17.26 \mathrm{ab}$ & $29.21 \mathrm{i}$ & $26.33 f$ & 21.21 cdef \\
\hline CDF & $11.01 I$ & $31.06 \mathrm{hi}$ & 44.27 a & $78.16 a$ \\
\hline D1 U.C. & 13.42 ghij & 34.59 cdefg & $19.85 \mathrm{hi}$ & $12.81 \mathrm{def}$ \\
\hline $\begin{array}{l}\text { Producto } \\
\text { final }\end{array}$ & 11.31 I & $21.03 \mathrm{j}$ & $14.36 \mathrm{j}$ & 7.54 ef \\
\hline
\end{tabular}

Nota: UA: Unidades de Absorbancia. T1: triturador 1; T2: triturador 2; T3: triturador 3; $\mathrm{C} 1 \mathrm{H} 1$ : corriente 1, harina 1; $\mathrm{C} 2 \mathrm{H} 1$ : corriente 2, harina 1; $\mathrm{C} 2 \mathrm{H3}$ : $\mathrm{CO}-$ rriente 3 , harina $3 ; \mathrm{C} 3 \mathrm{H} 1$ : corriente 3 , harina $1 ; \mathrm{C} 3 \mathrm{H} 2$ : corriente 3 , harina $2 ; \mathrm{C} 3$ $\mathrm{H} 3$ : corriente 3 , harina 3 ; $\mathrm{C} 4 \mathrm{U} . \mathrm{C}$ : corriente 4 ; $\mathrm{C} 5 \mathrm{H} 1$ : corriente 5 , harina $1 ; \mathrm{C} 5$ $\mathrm{H} 2$ : corriente 5 , harina 2; $\mathrm{C} 6 \mathrm{H} 1$ : corriente 6 , harina 1 ; $\mathrm{C} 6 \mathrm{H} 2$ : corriente 6 , harina 2; C7 U.C: corriente 7; C8 U.C: corriente 8; C9 U.C: Corriente 9; CDF: Centrífugo de fuerza; Div 1: divisor 1; Div 2: divisor 2; Div C: divisor cepillador; D1: reductor 1; Producto final, harina comercial. Dentro de una columna, promedios con la misma letra no muestran diferencias sianificativas $(\mathrm{p}>0.05)$.
En la figura 2 A se muestran los patrones de separación en electroforesis desnaturalizante y reductora (SDS-PAGE) de las proteínas totales de las harinas de las corrientes de molienda. La región del gel donde se identifican las bandas que corresponden a las subunidades de gluteninas de peso molecular bajo tipo D (G-BPM) y las gliadinas $\omega$, muestra claras diferencias entre las corrientes. Las corrientes presentadas en el electroferograma provienen del sistema de purificación, de reducción y el producto final. Se pueden observar diferencias en la presencia de estas bandas, así como en la intensidad, relacionada con la concentración de estas proteínas en la solución estudiada. Estos resultados, sugieren una segregación proteica en el proceso de molienda, por lo que la fracción proteica de G-BPM tipo D y gliadinas $\omega$ varia cualitativamente en las corrientes de harina de trigo. También se realizó la separación por electroforesis desnaturalizante y reductora (SDS-PAGE) de las proteínas a las cuales se le extrajeron las proteínas de la fracción soluble en propanol al $50 \%$, en donde se incluyen las gliadinas. El electroferograma de la figura 2 B, muestra la separación de las subunidades de gluteninas; no se encontraron diferencias tan notorias en cuanto a la presencia de las subunidades tipo D, pero si en la intensidad, y estos resultados confirman que la diferencia cualitativa más importante entre las proteínas de las harinas de las diferentes corrientes se da en la subclase de las gliadinas omega.

\section{Relación de componentes e indicadores de calidad}

Los resultados obtenidos del análisis multivariado de componentes principales, se muestra en la figura 3; se observa que dos factores son los que explican el $63.8 \%$ de la variabilidad. Se observa una correlación positiva de las dimensiones de PT, contenidos de albuminas, globulinas y ceniza, con el factor 1 (F1), mientras que se muestra una correlación negativa en las dimensiones de PPI e índice de sedimentación y una correlación positiva de PPS, gliadinas y contenido de humedad en el factor 2 (F2). Se puede observar que las variables PPI e índice de sedimentación se relacionan en forma positiva, pero, aunque las dos son índices de calidad de panificación, obviamente miden cosas diferentes.

Estos resultados confirman que las proteínas provenientes de la parte externa del endospermo son de menor calidad (albuminas y qlobulinas) y se encuentran en mayor

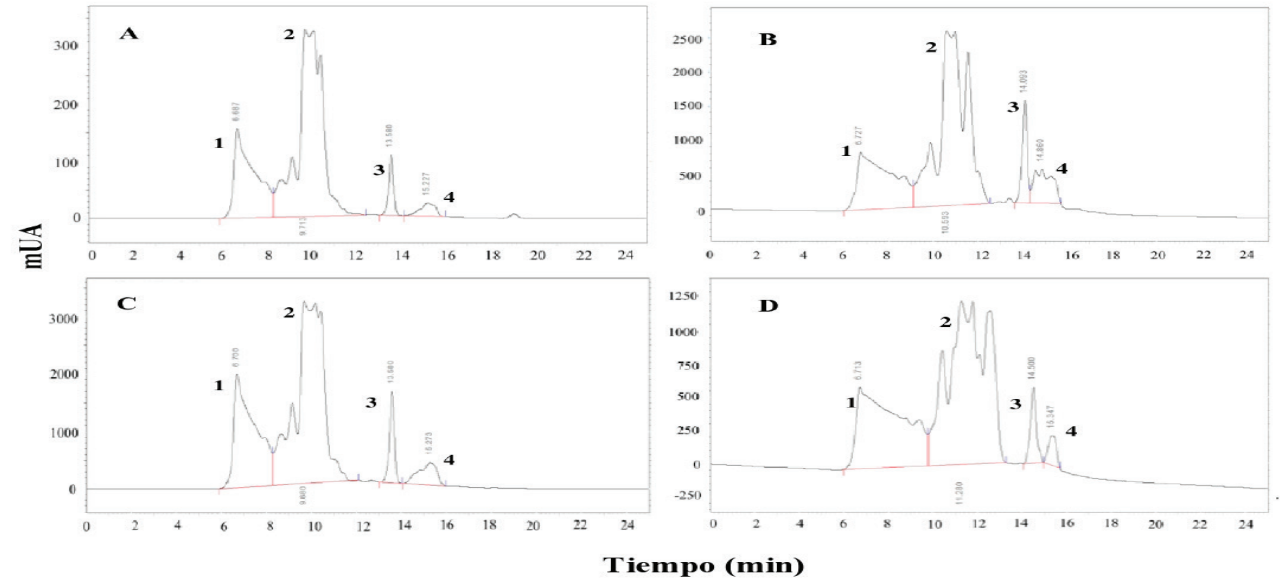

Figura 1. Gráficas de la cromatografía liquida de exclusión molecular de las corrientes de trigo; A: triturador 1 ; B: corriente 4; C: divisor 2; D: producto final; pico 1: proteína polimérica soluble (PPS); 2: gliadinas; 3: albuminas; 4: globulinas.

Figure 1. Chromatograms of high performance molecular exclusion liquid chromatography on wheat millstreams: A: break roll 1; B: stream 4; C: divider 2: D: final product. Peak1: soluble polymeric protein (PPS); peak 2: gliadins; peak 3: albumins; 4: globulins. 


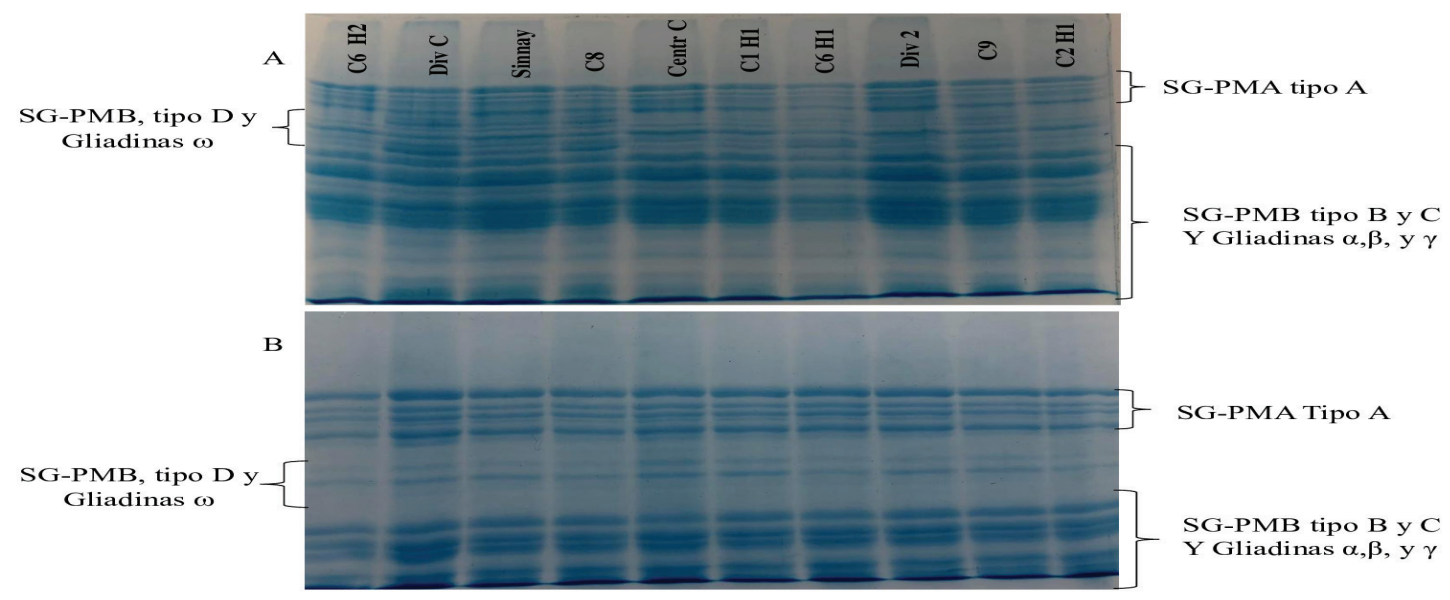

Figura 2. A: SDS-PAGE de proteínas totales, de harinas de corrientes de molienda. B: SDS-PAGE de proteínas de harinas de las mismas corrientes, en donde se removieron albúmins, globulinas y gliadinas. $\mathrm{C} 6 \mathrm{H2}$ : corriente 6, harina 2; Div C: divisor cepillador; Sinnay: producto final; $\mathrm{C} 8$ : corriente 8; Centrifugo 2; $\mathrm{C} 1 \mathrm{H1}$ : corriente 1, harina 1, $\mathrm{C} 6 \mathrm{H1}$ : corriente 6, harina 1, Div 2, divisor 2, C9: corriente 9 , $\mathrm{C} 2 \mathrm{H1}$ : corriente 2, harina 1. SG-PMA, subunidades de gluteninas de peso molecular alto; SG-PMB, subunidades de gluteninas de peso molecular bajo.

Figure 2. A: SDS-PAGE of total flour proteins on millstreams. B: SDS-PAGE of flour proteins on millstreams, where albumin, globulins and gliadins were removed. C6 H2: stream 6, flour 2; Div C: Brusher divider; Sinnay: final product; C8: stream 8; Centr 2: centrifuge 2; C1 H1: stream 1, flour 1, C6 H1: stream 6, flour 1, Divisor 2: Divider 2, C9: Stream 9, C2 H1: Stream 2 Flour 1. SG-PMA, High molecular weight glutenin subunits; SG-PMB: low molecular weight glutenin subunits.

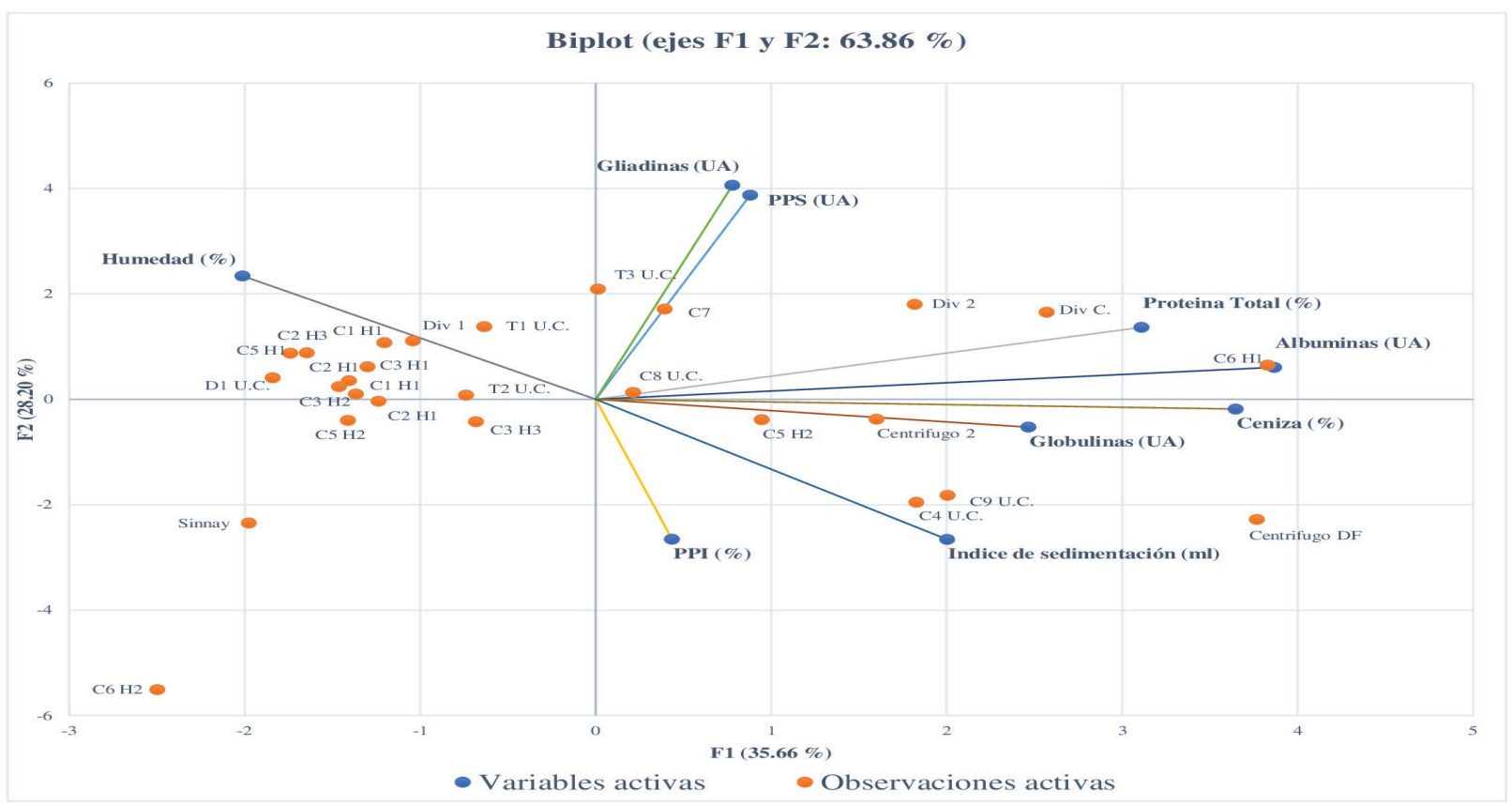

Figura 3. Análisis de componentes principales. Las dimensiones del análisis son: Humedad (\%), PPS (proteína polimérica soluble UA), gliadinas (UA), proteína total (\%), albuminas (UA), ceniza (\%), globulinas (UA), índice de sedimentación (mL) y PPI (proteína polimérica insoluble \%). Centrifugo DF: Centrifuga de fuerza, Centrifugo 2, C9 U.C.: Corriente 9 Única Corriente; C4: Corriente 4 única corriente; C6 H1: Corriente 6 Harina 1, C6 H2: Corriente 6 Harina 2, C1 H1: Corriente 1 Harina 1, T3 U.C.: Triturador 3 Única Corriente, T2: Triturador 2; D1: Reductor; C3 H3: Corriente 3 Harina 3; T1: Triturador 1; C3 H2: Corriente 3 Harina 2; C3 H1: Corriente 3 Harina 1; C2 H1: Corriente 2 Harina 1; C2 H3: Corriente Harina 3; Sinnay: Producto final; Div. 1: Divisor 1; C5 H2: Corriente 5 Harina 2; C5 H1: Corriente 5 Harina 1; C8 U.C.: Corriente 8 Única corriente; C7: Corriente 7; Div 2: Divisor 2; Div C: Divisor Cepillador; (UA): Unidades de Absorbancia. Figure 3. Principal component analysis. The dimensions of the analysis are: moisture (\%), SPP soluble polymeric protein (UA), gliadins (UA), total protein (\%), albumins (UA), ceniza (\%), globulinas (UA), sedimentation index $(\mathrm{mL})$ y PPI (Insoluble polymeric protein \%). Centrifugo DF: Centrifuge, Centrífugo 2, C9 U.C.: Stream 9 unique stream; C4: Stream 4 unique stream; C6 H1: stream 6 flour 1, C6 H2: stream 6 flour 2, C1 H1: stream 1 flour 1, T3 U.C.: Break roll 3 unique stream, T2: Break roll 2; D1: Reduction roll; C3 H3: stream 3 flour 3; T1: Break roll 1; C3 H2: stream 3 flour 2; C3 H1: stream 3 flour 1; C2 H1: stream 2 flour 1; C2 H3: stream 2 flour 3; Sinnay: Final product; Div. 1: Divider 1; C5 H2: stream 5 flour 2; C5 H1: stream 5 flour 1; C8 U.C.: stream 8 unique stream; C7: Stream 7; Div 2: Divider 2; Div C: Divider brusher; (UA): Absorbance units. 
cantidad cercanas al pericarpio, mientras que en la parte nuclear del endospermo podemos encontrar la PPI, la cual se correlaciona de forma positiva con el parámetro fisicoquímico de índice de sedimentación.

El grano trigo presenta una distribución no homogénea de sus componentes, debido a las diferencias de composición de las estructuras anatómicas y también a la distribución no homogénea de los componentes del endospermo, especialmente el contenido de proteína. La parte más externa del endospermo presenta un mayor contenido de proteína, pero no necesariamente de mejor calidad panadera, ya que tiene mayor proporción de albúminas, globulinas y gliadinas (Tosi et. al., 2011; Tosi et. al., 2018). Además, el proceso de molienda de rodillos se basa en la separación de los componentes anatómicos, por lo que podemos esperar una gran variación en la composición y calidad de las harinas obtenidas de las diferentes corrientes de molienda.

Las harinas obtenidas en los pasos de reducción de los trozos de endospermo y dependiendo de la localización inicial en el grano, producen harinas de mejor calidad panadera, ya que se encuentran con menos contaminación con partículas provenientes de las capas más externas del grano, de la capa aleurona principalmente y mayor contenido de gluteninas insolubles (PPI).

Debido a la variación tan marcada en el contenido y calidad de las proteínas, se pueden esperar, también una variación muy importante en la calidad panadera. En este caso se usaron dos indicadores de calidad: proteína polimérica insoluble (PPI) que es el porcentaje de proteína que no se extrae con la solución alcohólica de propanol al 50\%, y el volumen de sedimentación. La proteína polimérica insoluble se relaciona con la fuerza de la masa (Gupta et. al. 1993; Bean et. al. 1998) y el volumen de sedimentación con la calidad de proteína que redunda en un mayor volumen de pan. Estos dos indicadores se relacionaron positivamente entre si, pero no en forma muy estrecha o cercana. Podemos decir de los resultados obtenidos, que para obtener una estimación de la calidad panadera de una harina, cuando no se utiliza la prueba definitiva de panificación, es necesario evaluar los dos indicadores. Debido a la complejidad del sistema de panificación, desde el punto de vista de las interacciones proteicas responsables de la fuerza y la extensibilidad de las masas, se hace necesario para obtener una correcta predicción de la calidad de panificación, el uso de los dos indicadores.

\section{CONCLUSIONES}

El estudio del contenido y calidad proteica en las harinas de corrientes de un molino de trigo panadero comercial, mostró que en el sistema de reducción y centrifugas se encuentran las harinas con mejor distribución de las fracciones proteicas. El índice de sedimentación mostró una relación positiva con la PPI sugiriendo corrientes de estas características con potencial panificador.

Las diferencias cualitativas más importantes en la composición proteica de las harinas provenientes de las diferentes corrientes, se encuentra en la fracción de las gliadinas omega. Se confirma además el aumento gradual de las proteínas albuminas y globulinas en las ultimas corrientes de cada proceso y la fuerte correlación con el contenido de ceniza y con contenido de proteína (PT). La proteína de mayor calidad se encuentra en las primeras harinas de cada sistema, a las que se le llama harinas de primera calidad.

\section{AGRADECIMIENTOS}

Los autores agradecen a Osvaldo Castro Sotelo y Reyna López Montes por su colaboración y por su invaluable apoyo en el desarrollo del trabajo realizado en el molino harinero. También a la empresa molinera Grupo MUNSA, S.A. de C.V. por su apoyo para la realización del presente trabajo de investigación y el desarrollo de la tesis de maestría del autor principal.

\section{REFERENCIAS}

AACC. 2020. Approved Methods of Analysis, 11th ed. Metods: 08-01.01; 44-40; 56-60.01. Cereals and Grains Association, St. Paul, MN, USA.

Bean, S. R., Lyne, R. K., Tilley, K. A., Chung, O. K., \& Lookhart, G. L. 1998. A rapid method for quantitation of insoluble polymeric proteins in flour. Cereal Chemistry 75: 374-379.

Brütsch, L., Huggler, I., Kuster, S., \& Windhab, E. J. 2017. Industrial roller milling process characterisation for targeted bread quality optimization. Food and Bioprocess Technology. 10: 710-719.

Campbell, G. M., Fang, C., \& Muhamad, I. I. 2007. On predicting roller milling performance VI: Effect of kernel hardness and shape on the particle size distribution from first break milling of wheat. Food and Bioproducts Processing. 85: 7-23.

Dube, R., Indrani, D., Leelavathi, K., \& Sidhu, J. S. 1987. Flour mill streams. I. Physico-chemical and rheological characteristics. Indian Miller. 18: 17-19.

Every, D., Simmons, L., Al-Hakkak, J., Hawkins, S., Ross, M., 2002. Amylase, falling number, polysaccharide, protein and ash relationships in wheat millstreams. Euphytica 126: 35-142.

Gupta, R.B., Khan, K. \& Macritchie, F. 1993. Biochemical basis of flour properties in bread wheats. I. Effects of variation in the quantity and size distribution of polymeric protein. Journal of Cereal Science 18: 23-41.

Kent, N. L. 1966. Technology of Cereals, with Special Reference to Wheat. $2^{\text {a }}$ ed. Oxford, Pergamon Press Limited label, New York, NY, USA.

Laemmli, U.K. 1970. Cleavage of structural proteins during the assembly of the head of bacteriophage T4. Nature 227: 680685.

Liu, Y., Ohm, J. B., Hareland, G., Wiersma, J., \& Kaiser, D. 2011. Sulfur, protein size distribution, and free amino acids in flour mill streams and their relationship to dough rheology and breadmaking traits. Cereal Chemistry. 88:109-116.

Nelson, P. N. \& McDonald, C. E. 1977. Properties of wheat flour protein in flour from selected mill streams. Cereal Chemistry. 54: 1182-1191.

Okrajková, A., Prieto-Linde, M., Muchová, Z., \& Johansson, E. 2007. Protein concentration and composition in wheat flour mill streams. Cereal Research Communications. 35: 119-128. 
Payne, P.I., Law, C. N., \&Mudd, E.E. 1980. Control by homoeologous group 1 chromosomes of the high-molecular-weight subunits of glutenin, a major protein of wheat endosperm. Theoretical and Applied Genetics, 58:113-120.

Pomeranz Y. 1988. Wheat Chemistry and Technology. $3^{\text {rd }}$ ed. American Association of Cereal Chemists, St. Paul, Minnesota, USA.

Pojic, M. M., Spasojević, N. B., \& Atlas, M. Đ. 2014. Chemometric approach to characterization of flour mill streams: chemical and rheological properties. Food and Bioprocess Technology. 7: 1298-1309.

Sakhare, S. D., Inamdar, A. A., Indrani, D., Kiran, M. M., \& Rao, G. V. 2015. Physicochemical and microstructure analysis of flour mill streams and milled products. Journal of Food Science and Technology. 52: 407-414.

Shewry, P. R. 2009. Wheat. Journal of experimental botany. 60(6), 1537-1553.

Suresh, A. \& Neethirajan, S. 2015. Real-time 3D visualization and quantitative analysis of internal structure of wheat kernels. Journal of Cereal Science. 63: 81-87.
Sutton K.H. \& Simmons L.D. 2006. Molecular level protein composition of flour mill streams from a pilot-scale flour mill and its relationship to product quality. Cereal Chemistry. 83: 52-56.

Tosi, P., Gritsch, C. S., He, J., \& Shewry, P. R. 2011. Distribution of gluten proteins in bread wheat (Triticum aestivum) grain. Annals of Botany. 108: 23-35.

Tosi, P., He, J., Lovegrove, A., Gonzales-Thuillier, I., Penson, S. \& Shewry, P. 2018. Gradients in compositions in the starchy endosperm of wheat have implications for milling and processing, Trends In Food Science \& Technology. 82:134139.

Wang, Y. G., Khan, K., Hareland, G., \& Nygard, G. 2007. Distribution of protein composition in bread wheat flour mill streams and relationship to breadmaking quality. Cereal Chemistry. 84: 271-275. 